\title{
Livelihood and vulnerability in the wake of Typhoon Yolanda: lessons of community and resilience
}

\author{
Pauline Eadie $^{2}$ (D) Maria Ela Atienza ${ }^{1} \cdot$ May Tan-Mullins ${ }^{3}$ (D)
}

Received: 14 July 2018 / Accepted: 24 April 2020 / Published online: 13 May 2020

(c) The Author(s) 2020

\begin{abstract}
Livelihood strategies that are crafted in 'extra-ordinary' post-disaster conditions should also be able to function once some semblance of normalcy has resumed. This article aims to show that the vulnerability experienced in relation to Typhoon Yolanda was, and continues to be, directly linked to inadequate livelihood assets and opportunities. We examine the extent to which various livelihood strategies lessened vulnerability post-Typhoon Yolanda and argue that creating conditions under which disaster survivors have the freedom to pursue sustainable livelihood is essential in order to foster resilience and reduce vulnerability against future disasters. We offer suggestions to improve future relief efforts, including suggestions made by the survivors themselves. We caution against rehabilitation strategies that knowingly or unknowingly, resurrect pre-disaster vulnerability. Strategies that foster dependency, fail to appreciate local political or ecological conditions or undermine cooperation and cohesion in already vulnerable communities will be bound to fail. Some of the livelihood strategies that we observed post-Typhoon Yolanda failed on some or all of these points. It is important for future policy that these failings are addressed.
\end{abstract}

Keywords Livelihood · Disaster resilience · Philippines · Vulnerability · Typhoon Haiyan (Yolanda)

Pauline Eadie

Pauline.Eadie@nottingham.ac.uk

Maria Ela Atienza

ela_atienza@yahoo.com

http://polisci.upd.edu.ph/faculty/atienza.html

May Tan-Mullins

May.TAN-MULLINS@nottingham.edu.cn

1 Department of Political Science, University of the Philippines, 2nd Floor, Bulwagang Silangang Palma/CSSP Faculty Centre, Roxas Ave. cor. Africa St., Diliman, 1101 Quezon City, Philippines

2 Institute of Asia Pacific Studies, School of Politics and International Relations, University of Nottingham, University Park, Room C8 Law and Social Sciences Building, Nottingham NG7 2RD, UK

3 School of International Studies, The University of Nottingham Ningbo China, 199 Taikang East Road, AB313, Ningbo 315100, China 


\section{Introduction}

Livelihood can be threatened by a complex array of issues such as disasters and wars, which could deprive households of productive assets and access to markets, and potentially disrupt livelihood related mutual support mechanisms that often exist in poor communities. In this article, we argue that strategies to restore livelihood after a disaster must be devised so that they can function effectively under 'ordinary', as opposed to 'extraordinary' conditions (or times). Ordinary and extraordinary are not polar opposites; they are points on a shifting and complex matrix of socio-economic life and the impact of disasters. Ordinary conditions may include, but are not limited to, exposure to various anticipated risks such as seasonal storms and flooding, inadequate shelter, discrimination on the basis of ethnicity, age or gender, limited livelihood related capability or governmental inadequacy. These are at times structural and consistent conditions that could happen on a regular basis. Disasters such as super typhoon Yolanda (international name Haiyan) are considered to be extraordinary. They are extreme in terms of their sheer scale and severity, are unusually disruptive and result in unanticipated impacts.

In the aftermath of Typhoon Yolanda thousands of aid workers arrived in the disaster zone and millions of dollars in foreign aid poured into the local economy in support of the humanitarian relief and rehabilitation effort. Many agencies stayed for up to 2 years, some for longer, creating new opportunities for business, investment and local employment but demand also increased for local goods and service, inflating prices and creating jobs (Secret Aid Worker 2015). However, when aid agencies move on, and the post-disaster economic bubble ${ }^{1}$ has run its course, a return to socio-economic 'normalcy' may be suboptimal, impossible or hard to quantify. Nevertheless, livelihood strategies created in the aftermath of a disaster should still be viable in 'ordinary' circumstances. For livelihood initiatives to be truly sustainable, they should be capable of reducing vulnerability over the longer term and making the 'ordinary' better.

Human vulnerability is a multi-dimensional and dynamic condition. Age, gender, disability, sexuality, ethnic difference, locality and levels of wealth can all influence how vulnerable people are to specific threats and how these threats are perceived and experienced. Poor individuals or communities may not, on the face of it, appear insecure as they are functioning and their vulnerability may be latent. However, natural hazards can expose this latent vulnerability that poor communities live with on a daily basis. When this exposure is sudden, as in the case of major typhoons or earthquakes, the impact of the event dictates that the event itself and the subsequent relief effort is presented in 'extraordinary' terms.

This was the case when Typhoon Yolanda struck the Eastern Visayas region of the Philippines on 8 November 2013. It was one of the strongest typhoons ever to make landfall with wind speeds up to $315 \mathrm{kms}$ per hour and a strong surge that reached six metres in places. More than 6000 people died, 1785 were reported missing and 28,626 were injured (National Operational Assessment of Hazards, n.d.). The total number of people affected

\footnotetext{
1 In the aftermath of disasters, asset bubbles can be created whereby the cost of goods and services are rapidly inflated due to demand generated by aid influx. Such assets could include e.g. catering and accommodation, office space, interpreters, drivers and labourers, construction materials and machinery or water. Where local economies rely on sectors significantly affected by the disaster such as tourism, farming or fisheries, and piecemeal own account working is common dependence on the disaster economy is likely to be higher. This means that when demand contracts and asset prices fall, or the bubble bursts, the local economy could end up worse off than before the disaster.
} 
by Typhoon Yolanda, in relation to their livelihood, environmental and food security, was approximately 16 million. The livelihoods of 5.9 million people were 'destroyed, lost or disrupted' (OCHA/UNEP 2014: 5) by Typhoon Yolanda.

Building on the earlier work of Cannon et al. (2003), we argue that post-disaster livelihood strategies that are informed by a central reference point of vulnerability (during the 'ordinary' times) could help build more resilient futures. We argue that ex ante livelihood 'buffers' (Marschke and Berkes 2006; Scoones 1998) could help reduce vulnerability and that these buffers should be mainstreamed into disaster risk reduction (DRR). We have chosen to focus on livelihood because this issue was central to the rehabilitation efforts post-Typhoon Yolanda and is more broadly a key driver of sustainable post-disaster recovery. In connection with the other related literature, livelihood is one of two (the other being housing) aspects of recovery that 'play a critical role in the perception of affected individuals about their general recovery after disasters' (Taheri Tafti and Tomlinson 2015: 168).

The communities examined in this article are all located in the adjacent Local Government Units (LGUs) of Palo, Tanauan and Tacloban City, in the Eastern Visayas region (also known as Region VIII) of the Philippines. This region bore the brunt of Typhoon Yolanda in November 2013. Governance in the Philippines is devolved through a system of LGUs, namely provinces, cities, municipalities, and barangays (the smallest politicaladministrative units) run by elected officials. LGUs have various powers that are devolved from the national government under the 1991 Local Government Code (Brillantes 1998). Palo is a third class municipality and Tanauan is designated second class; government classification is based on income. Tacloban is a highly urbanised city with a population of over 242,089 in 2015 (Philippines Statistics Authority 2016) and an annual income over 50 million PHP (constant price using 1991 as base year).

The Visayas islands are home to some of the poorest provinces in the Philippines ${ }^{2}$. The three areas were chosen as the focus of this study as they were at the centre of a massive and prolonged international relief effort. They are not conflict zones; however, many coastal dwellers lived 'close to the subsistence level and [were] thus structurally positioned at the edge of socio-economic disaster' (Siar 2003: 272). In this case, socio-economic disaster was triggered by a 'natural disaster', Typhoon Yolanda. An assessment of the extent to which relief strategies reduced or increased vulnerability via livelihood, is one useful way of testing whether disaster relief strategies really managed to foster resilience after Typhoon Yolanda. As vulnerability is understood and experienced in many different ways, this article draws on a wide range of primary survey and interview data gathered in our chosen communities.

This article first outlines our data gathering strategies and elaborates on vulnerability as a conceptual framework. We then summarise the different concepts such as livelihood, resilience, disasters and vulnerability and their relation to each other. We argue that the vulnerability experienced in relation to Typhoon Yolanda was, and continues to be, directly linked to inadequate livelihood assets and opportunities. The next section examines the pre-disaster vulnerability that existed during 'ordinary' conditions. This is followed by an assessment of how post-disaster interventions during 'extraordinary' circumstances contributed, or did not contribute, to resilience and lessening of vulnerability. The final section

\footnotetext{
${ }^{2}$ A distinction can be made within the Visayas with Eastern, Northern and Western Samar provinces recording higher poverty rates than Leyte (most number of poor families) and being in the top ten poorest provinces of the Philippines together with Negros Oriental in 2012 (NAPC). However, in the first half of 2014, Eastern Visayas (Region VIII) became the poorest region in the country (NSCB 2015).
} 
summarises our findings and we conclude by cautioning against rehabilitation strategies that knowingly or unknowingly, resurrect pre-disaster vulnerability. Strategies that foster dependency, fail to appreciate local political or ecological conditions or undermine cooperation and cohesion in already vulnerable communities will be bound to fail.

\section{Data gathering}

In this article, we use a comparative and mixed methods approach using quantitative and qualitative data. Evidence is drawn mostly from 20 barangays of comparable size across three LGUs: eight in Tacloban City, six in Palo and six in Tanauan. The uneven sample size across the LGUs relates to the differing size, and hence number of barangays, within each LGU. Assessing post-disaster activity across space at the barangay level allowed us to compare what strategies worked better or worse in similarly impacted, but different, localities in terms of post-disaster resilience building. This is important as community resilience building is best understood from the bottom up in order to avoid 'disaster management interventions [that] have a propensity to follow a paternalistic mode that can lead to the skewing of activities towards supply rather than demand' (Manyena 2006: 438).

Coastal geography alone dictated our choice of barangays $^{3}$, and we had no prior assumptions about the degree of social cohesion or effective leadership and capacity building within each barangay. This paper is based on the premise that there was great value in information drawn directly from local 'communities' that had lived experience of the disaster and its aftermath. We treat communities as being a group of people living within the geographically and politically defined area of a barangay. These communities are linked by family ties and embedded interaction between neighbours, especially where populations are stable. However, such communities do not operate in isolation. Networks of social interaction and joint action that impacted upon these communities operated at a number of levels including locally, nationally and internationally. The idea of community is important as without 'community participation, disaster relief often inadvertently rebuilds [...] structures of vulnerability' (Bhatt and Reynolds 2012: 74).

Vulnerability is a material and social condition and, to a certain extent, subjective. Therefore, we aimed to gather a broad range of data on the material and social experience of rehabilitation as systematically as possible. We interviewed a sample of the population large enough to allow for the cross-checking of responses and conducted about 800 household surveys annually in 2015, 2016 and 2017. This allowed us to identify general trends in how the rehabilitation efforts were perceived and experienced across time and space and teased out the nuances of power relations between the different stakeholders. The data cited in this paper refers only to the survey responses that directly address livelihood. We instructed our fieldworkers to survey an equal balance of men and women; nevertheless, our respondents were predominately female: 61 per cent in 2015, 74.7 per cent in 2016 and 75 per cent in 2017. As our surveys were conducted during daylight hours this gender imbalance was indicative that it was predominantly women who were at home during the working day.

Semi-structured interviews were also conducted with a range of governmental and nongovernmental stakeholders over 4 years from 2014 to 2018 . We interviewed each barangay

\footnotetext{
3 The barangays chosen were: Tacloban: Barangays 54, 54-A, 66-A, 67, 87, 88, 89, and Abucay (least affected); Palo: Cavite, Cogon, Libertad (least affected), Pawing, Salvacion, and San Joaquin; and Tanauan: Bislig, Calogcog, Salvador (least affected), San Roque, Sta. Cruz, and Sto. Niño.
} 
captain (or representative) and mayor annually for the duration of our project. Twenty-four focus group discussions with various sectors including women, the elderly, youth, persons with disabilities and mixed groups, across the three LGUs were held over 3 years. We also identified two families in each barangay, one most affected and one least affected, that were willing to be interviewed year on year. By selecting 20 most affected and 20 least affected families, we aimed to establish the factors that helped or hindered disaster recovery given their similar but perhaps different experiences. We asked every family the same questions. By interviewing 40 families in a semi-structured and systematic fashion, we aimed to go beyond mere anecdotal evidence.

The virtue of gathering evidence over time is that we were able to monitor first-hand the extent to which relief operations ameliorated the vulnerability of communities beyond the initial emergency phase. We were able to go back to the same communities and the same respondents to see whether their situation had improved or changed and what the primary obstacles were to their rehabilitation. We were also able to observe the shift in activity when many international aid agencies left and tease out the sustainability of these livelihood strategies in both extraordinary and ordinary conditions. The production of both quantitative survey data and qualitative interview data allowed us to compare quantitative trends with rich empirical data from interviews. Gathering data from a range of stakeholders allowed us to assess how livelihood strategies were both produced and applied and to compare the stated aims and objectives of the strategies with how they were actually experienced.

We also took note of the existing institutional governance structures. While the form of government is unitary, devolution was established in the Philippines via the 1991 Local Government Code (Republic Act No. 7160). The Code devolved wide-ranging responsibilities to LGUs, including disaster response and management (Atienza et al. 2019). Furthermore, the Philippine Disaster Risk Reduction and Management Act of 2010 (Republic Act No. 10121), in setting up the National Disaster Risk Reduction and Management Framework as well as the National Disaster Risk Reduction and Management Council (NDRRMC), puts in the frontline both the national government and LGUs (Eadie 2019: 93-94). LGUs are mandated to have their own local DRRM budgets, plans, and offices. The national DRRM framework also enables various government agencies at various levels not only to coordinate with each other but with civil society organizations as well as international and foreign bilateral agencies.

A consideration of the prevailing governance structures helps us to assess some of the institutional factors that affected the sustainability of the livelihood strategies introduced in the three areas that we studied. It is also useful to reflect on whether there were problems with the governance structures themselves or only in policy implementation.

\section{Resilience, livelihood, disaster and vulnerability}

Resilience has been debated across disciplines in physical/material and social terms. ${ }^{4}$ The word resilience is derived from the Latin word resilio meaning to leap or spring back. It can be defined as 'the capacity of any entity - an individual, a community, an organisation, of a natural system - to prepare for disruptions, to recover from shocks and stresses,

\footnotetext{
${ }^{4}$ For conceptual overviews of the term resilience as they relate to disaster relief see: Alexander (2013), Cote and Nightingale (2012), Manyena (2006) and Mitchell and Harris (2012), Weichselgartner and Kelman (2014).
} 
and to adapt and grow from a disruptive experience' (Rodin 2015: 3). Resilience does not just relate to the ability to deflect and counter threats; it is also about physical and social adaptation. Therefore, resilience can be equated to capabilities. Ideally survivors should have the capabilities to reduce their own vulnerability and work towards a resilient future. Resilience may be subjective and 'comparable disasters could generate quite different articulations of resilience from similarly affected communities' (Eadie 2019: 98). Vulnerability and resilience can also coexist. From the outside, vulnerable communities may look like their ability to take action is constrained but the various hardships faced on a daily basis can mean that resilience is inbuilt. People are used to coping with living in close proximity to each other, economic stress and environmental threats. Therefore, coping strategies and 'psychological resilience' (Usamah et al. 2014: 187) are quickly activated during disasters.

Livelihood, as a means of resilience, needs to be understood in a framework of changing social, political, economic and environmental contexts (Davidson-Hunt and Berkes 2003; de Haan and Zoomers 2005; Delisle and Turner 2016). Indeed, the notion of livelihood itself should be seen in context: 'livelihood is a larger, more universal and more useful concept for seeing what best to do, encompassing as it does for many of the poor so much more than the employment of a job, which for many is not and cannot be a reality' (Chambers 1995: 183). Livelihood is not just a salary or a job; it is about the various ways that individuals and communities sustain themselves. Livelihood is commonly defined as, 'the capabilities, assets (both natural and social) and activities required for a means of living: a livelihood is sustainable when it can cope with and recover from stresses and shocks, maintain or enhance capabilities and assets, both now and in the future, while not undermining the natural resource base' (Chambers and Conway 1992: 7).

Livelihood is socially and ecologically situated. How intangible assets such as skills and social support, and tangible assets such as finance and ecological resources are accessed is an important determinant of livelihood (Bebbington 1999; Sok and Xu 2015). Many of the world's poor secure a living via the creation of multiple strategies that cannot be quantified on the basis of income alone. The poor exist in conditions that are 'local, complex, diverse and dynamic' (Chambers 1995: 173) and inevitably impact on the lived experience of the search for livelihood.

Livelihood decisions may involve meeting immediate needs even if this increases future vulnerability, e.g. going into debt, skipping education to go to work or engaging in unhealthy or dangerous work. These trade-offs have to be seen within the context that they are made and how people rationalise their own circumstances, 'the constraints under which they make these decisions and the power relations at play' (Bebbington 1999: 2033). Wealth, access to credit and productive assets such as land (Borras and Franco 2005), institutional policy (Scoones 2009: 176-183), human ingenuity, skills, training, equipment and social networks are important capability indicators. Issues such as gender (Angeles and Hill 2009; Gaillard et al. 2015; Siar 2003), disability (Tabuga and Mina 2011; Yamagata 2015), culture and social norms can also dictate how livelihood assets are accessed and utilised. The livelihood opportunities of women may be compromised because they are expected to take on unpaid care work that impact on their 'share in the distribution of resources post-disaster because their productive and reproductive contributions remain undervalued, uncounted and unpaid' (Tanyag 2018: 566). These issues present us with a set of complex indicators that are not always easy to measure, isolate or replicate.

Livelihood activities play out in different ways in different places. Rural livelihoods are likely to involve a combination of 'different activities in a complex bricolage or portfolio of activities' (Scoones 2009: 172) that are closely connected to the natural environment and the rhythm of the seasons. However, the focus on capabilities and assets in relation to 
shocks and stresses also translates to the urban environment. The variables that affect rural dwellers such as access to land, the depletion of open access resources such as fisheries, shelter and credit, skills and training and a government that can be held to account for the well-being of the population play out in different ways in the urban context, but they are still relevant.

In relation to shocks and stress Ian Scoones suggests that livelihood 'buffers' can be created if (a) livelihood resources are kept in reserve, (b) single and multiple livelihood activities can be diversified and realigned so that if a particular activity or complementary set of activities come under threat, alternative livelihood options are still available, (c) risk to livelihood is 'pooled' so the threats are minimised, and (d) resilient systems are built so that shocks and stresses have less impact (Scoones 1998: 10). These strategies are laudable in relation to building sustainable livelihoods; however, such interventions are seldom easy in poor communities that may be functioning at a bare level of existence. Nevertheless, they are sound benchmarks against which vulnerability can be measured.

Such buffers are particularly important in areas prone to disasters and 'sustainable livelihood' approaches can provide a valuable opportunity for combining disaster reduction and development interventions in one unifying approach' (Sanderson 2000: 51). Sustainable livelihood approaches have typically focused on how human, social, physical, natural and financial capital can be 'assessed in terms of their vulnerability to shocks and the institutional context in which they exist' (Morse and MacNamara 2013: 19). For livelihood to be resilient, it should be adaptable in the face of adverse conditions, and if necessary be realigned or reinvented ex post in the face of sometimes drastically altered socio-economic or ecological realities. Careful attention to the capabilities and assets could help ameliorate future vulnerability and aid disaster recovery.

The United Nations (UN) defines disasters as 'a serious disruption of the functioning of a community or a society involving widespread human, material, economic or environmental losses and impacts, which exceeds the ability of the affected community or society to cope with its own resources' (UNISDR 2009: 9). Environmental events, such as typhoons or earthquakes, are only classed as disasters when populations are seriously overwhelmed by the impact. The social aspect of disasters is a common but important theme in disaster research. Wisner et al. acknowledge that disasters are products 'of social, political and economic environments because of the way these structure the lives of different groups of people' (2004: 4). The nature of this interplay is complex, contested and varies widely across time and space, meaning that 'disasters cannot be understood to be "natural" in any straightforward way' (Wisner et al. 2004: 9). Meanwhile, Daniel P. Aldrich highlights social systems and resources that are overwhelmed by disaster. Aldrich defines disasters as 'event[s] that suspend normal activities and threatens or cause severe, community wide damage' (2012: 3). The use of the word community is notable as disaster is seen to impact on some sort of collective that is not necessarily the state.

Disasters often have the greatest impact on the most vulnerable populations and 'disasters occur when natural hazards and human vulnerabilities interact' (Bacon 2014: 23). Vulnerability to disasters is heightened by poverty and measures to mitigate and prevent disasters that ignore 'underlying, hazard independent structural constraints' (Gaillard et al. 2009: 126), inevitably ending up treating the symptoms, as opposed to the root causes of vulnerability. Omar D. Cardona defines vulnerability as 'the physical, economic, political or social susceptibility or predisposition of a community to damage' (2004: 37). Meanwhile, Bankoff argues that 'vulnerable populations are created by particular social systems in which the state apportions risk unevenly amongst its citizens' (2003: 12). Not all poor people are at risk from disasters. Nevertheless, those who live in fragile housing in exposed 
localities or risky locations and lack access to financial or material safety nets (in other words buffers) are particularly vulnerable to calamities.

Indeed, as indicated by Rigg et al., 'natural events may appear cruelly random but their impacts, who they affect and how, the degree of resilience that societies and individuals exhibit, and the trajectories of recovery, are far from random' (2008: 138). As we can see from the above, there is consensus that vulnerability is socially determined. For this reason, an approach to disasters that focuses on vulnerability and widens the discussion to 'consider context, human rights and security more generally' (Brown and Westaway 2011: 333 ) is of value. For without social change, pre-existing vulnerability is likely to prevail in the aftermath of a disaster. This indicates that to devise sustainable livelihood in 'extraordinary' times in the aftermath of disasters, we need to re-evaluate the social injustice and vulnerability in the pre-disaster moments, i.e. the ordinary times.

This means getting 'back to normal' after a disaster is both a moving target and not necessarily an ideal state of affairs (Kelman et al. 2016: S137-S138). This is especially crucial when extreme weather events are arguably the new normal (Mondragon 2015; David et al. 2013; IPCC 2018) in countries where hurricanes, cyclones and typhoons or drought and high temperatures already appear with seasonal regularity. As such livelihood strategies need to be sustainable in environmental as well as socio-economic terms. There is also a tension between the need to devise sustainable livelihood strategies that ameliorate immediate and local shocks and stresses with the bigger picture of climate change. Thus far the literature on mainstreaming Disaster Risk Reduction and Management (DRRM) and development has tended to focus broadly on agriculture (Trujillo and Bass 2015), the physical environment (Chmutina and Bosher 2015; Wamsler 2006), governance (Tanner et al. 2019) and gender (Ginige et al. 2009; Khoza et al. 2019; Yumarni and Amaratunga 2018). A specific focus on the complexity of sustainable livelihood in both the 'ordinary' and 'extraordinary' is lacking. This is where this article will turn to next.

\section{Pre-disaster livelihood vulnerability (ordinary conditions)}

One day before Yolanda, on 7 November 2013, barangay captains and local government officials were tasked with encouraging people to go to designated evacuation centres or higher ground in anticipation of the coming super typhoon. National government leaders and agencies, through television and radio, warned of the strength of the coming typhoon. Key informants noted that while some followed the warning and evacuated, others remained or decided to stay at home to guard their property. Despite the vulnerability of their housing and coastal location, poor householders chose to stay put in the face of an impending disaster in order to safeguard their scarce possessions, which represented 'their life's work and sacrifices' (Dalisay and de Guzman 2016: 708-709). The coping strategies for many of the poor when warned of the imminent danger of a major typhoon was for the women and young children to evacuate to storm shelters whilst the men and older boys stay put and guard their houses and scarce possessions. This meant many of the men and older boys perished in the typhoon. This was evidenced by Bernardita Valenzuela, ${ }^{5}$ Head of Tacloban City Information Office and executive assistant to Mayor Alfred Romualdez, who described trying to convince a family to leave:

${ }^{5}$ Interview, November 11, 2015. 
I asked a fisher family to leave and said that the mayor has sent vehicles for them to go to the evacuation centre. The head of family responded, "Ma'am I cannot leave my house, my belongings and my pig". His pig is his means of livelihood [...] "What is the use of my life if I have no roof over my head and no food to put on the table for my family?" He said, "don't get angry Ma'am you bring my wife and my daughters" [...] He and his sons, they were all washed away (Valenzuela 2015).

People also refused to leave because they underestimated the impact of Yolanda. This led to the high casualty rate. We heard the phrase 'We were used to typhoons, but we did not expect the storm surge' repeatedly. A combination of past experience and the perceived importance of safeguarding livelihood assets and material goods meant that vulnerable householders were prepared to engage in 'risky' behaviour in the face of an incoming disaster. The 'buffers' discussed earlier in this article were either weak or absent in some cases. Even though the family above engaged in both fishing and raising a pig, the loss of the pig would have equated to the loss of a significant livelihood asset. In Region VIII as a whole, pre-Typhoon Yolanda (2012) statistics show that 24.9 per cent of the urban population were living in poverty. However, the numbers were much higher for certain groups e.g. 49.2 per cent of farmers, 46.4 per cent of fishermen and 40.4 per cent of self-employed or unpaid family workers (Philippine Statistics Authority 2016: 2-15) meaning that these groups were potentially more vulnerable to shocks and stresses. This gives credence to the argument that 'people and their vulnerability or resilience, instead of the physical implications of natural hazards, should be at the core of [disaster] analysis' (Bambals 2015: 150). Many people were vulnerable before Typhoon Yolanda and were subsequently left completely destitute in the aftermath of the disaster. Homes and possessions were swept away and family members were lost. The loss of tangible assets such as land, equipment (for example, tools, boats), livestock, crops and manpower from the household had a significant effect on livelihood.

\section{Post-disaster livelihood interventions (extraordinary conditions)}

USAID estimated that Typhoon Yolanda affected the income stream of 5.9 million, workers 'as a result of infrastructure damage, lack of access to markets, and disrupted cash flow' (USAID 2014: 2). Of those 5.9 million ' 44 per cent (2.6 million) of those affected were engaged in vulnerable employment as own account or contributing family workers with limited income and social security prior to the disaster' (ILO 2015: 11). 'Vulnerable employees', that is the self-employed who are directly dependent on the profit made from the goods and services produced, are most exposed to sudden and hurtful disruptions to livelihood.

Employment figures in the aftermath of Yolanda remained steady, most likely because of the multiple livelihood programmes available and the opportunities that came with the post-typhoon reconstruction fuelled economic boom. However, 47.7 per cent in 2013 and 50.4 per cent in 2014 of those classed as employed were working less than $40 \mathrm{~h}$ a week (Philippine Statistics Authority 2016b: 11.3) meaning that the line between employed and underemployed ${ }^{6}$ was perhaps questionable. Please see the table below for a list of

\footnotetext{
${ }^{6}$ Underemployment is when a person is employed but his/her labour is underutilized in terms of hours worked, skills used and compensation paid.
} 
Table 1 Livelihood Initiatives by Donor

\begin{tabular}{|c|c|}
\hline Name of organisation & Initiative \\
\hline $\begin{array}{l}\text { Dept. of Social Welfare and Development's } \\
\text { (DSWD) Sustainable Livelihood Program } \\
\text { (SLP) }\end{array}$ & $\begin{array}{l}\text { Livelihood Assistance Grants (LAG); Cash for Building } \\
\text { Livelihood Assets (CBLA); KALAHI-CIDDS Com- } \\
\text { munity Driven Development Project }\end{array}$ \\
\hline $\begin{array}{l}\text { Bureau of Fisheries and Aquatic Resources } \\
\text { (BFAR), Department of Agriculture }\end{array}$ & Fishing Boats \\
\hline WedPro & Livelihood programme \\
\hline Dept. of Labor and Employment (DOLE) & $\begin{array}{l}\text { Cash for work; Livelihood assistance including handi- } \\
\text { crafts, fishing and farming }\end{array}$ \\
\hline CONCERN/CECI & $\begin{array}{l}\text { Fisheries } \\
\text { Environmental Rehabilitation projects }\end{array}$ \\
\hline $\mathrm{ACF}$ & $\begin{array}{l}\text { Livelihood for fisherfolk } \\
\text { Unconditional Cash Transfer }\end{array}$ \\
\hline Oxfam & $\begin{array}{l}\text { Fishing Boats } \\
\text { Seaweed farming } \\
\text { Rice Seeds }\end{array}$ \\
\hline Dept. of interior and local governments (DENR) & $\begin{array}{l}\text { Fishing Boats } \\
\text { Ecotourism }\end{array}$ \\
\hline US government/USAID & Livelihood programmes, sari-sari stores \\
\hline Worldfish & $\begin{array}{l}\text { Aquaculture training } \\
\text { Milkfish production } \\
\text { Tilapia production }\end{array}$ \\
\hline Catholic Relief Services & Livelihood relief packages for farmers \\
\hline Tzu Chi & Cash for work \\
\hline UNDP & $\begin{array}{l}\text { Cash for work } \\
\text { Livelihood Diversification training }\end{array}$ \\
\hline
\end{tabular}

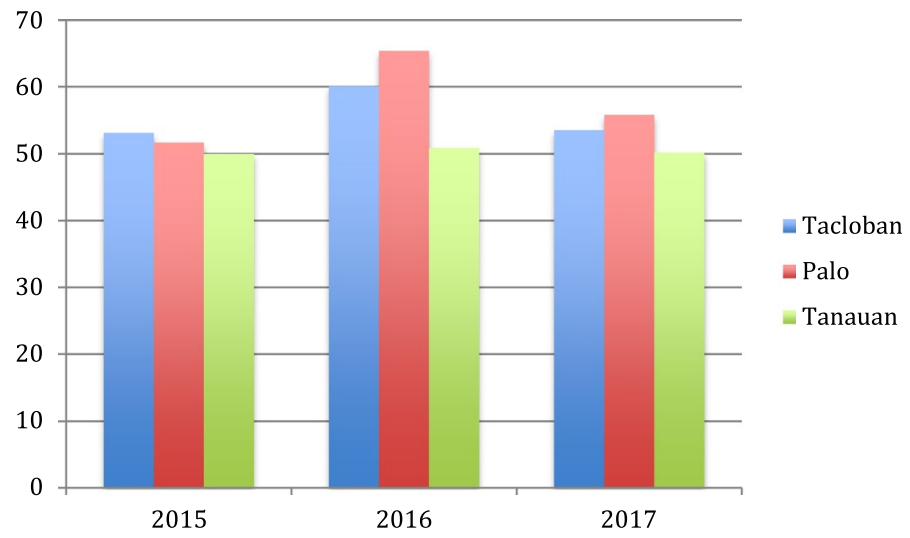

Fig. 1 Rate of unemployment based on authors' survey data. [For full survey results see (Berja 2015)]

livelihood initiatives mentioned by our informants. The list is non-exhaustive but gives an idea of the kinds of programmes offered by government and other agencies in operation post Yolanda (Table 1). 
Despite the relatively healthy employment figures detailed above, the predominantly female respondents in the barangays under investigation gave far higher rates of unemployment and underemployment than the official averages for Region VIII. As evidenced in the chart below (Fig. 1).

These figures are perhaps indicative that the region wide averages masked significant pockets of unemployment in the most vulnerable communities.

During our first survey round in 2015, 91.2 per cent of our survey respondents indicated that Typhoon Yolanda affected their livelihood. In 2016, 50 per cent reported that sourcing livelihood was more difficult in the time period since Yolanda and by 2017 this had dropped to 38 per cent. But despite this improvement over time 76 per cent in 2015, 82 per cent in 2016 and 83 per cent in 2017 reported that they had received no livelihood assistance or training. Before Typhoon Yolanda, most residents in the areas under investigation were engaged in the manufacturing and services sector, such as working in factories, and as sellers and traders and other labour-based jobs. However, less than half of our survey respondents living below the poverty threshold relied on salaries for their income, 33.2 per cent ran small businesses, 4.3 per cent received financial assistance of some sort, 1.9 per cent lived off a pension with 18.3 per cent citing 'other' sources of income. The diversity of activity reported as 'livelihood' reinforces the validity of Chambers' claim (1995: 191) that livelihood is a much more meaningful term than employment when capturing how people make a living. According to Chambers, 'on livelihood, the strategies of the poor are usually diverse and often complex' (1995: 192). Consequently, the measurement of monetary income as a determinant of sustainable livelihood may be problematic as income may be fluctuating, fragmented and fail to capture other forms of material exchange. The high level of non-salary income amongst the poor is also indicative that livelihood schemes and entrepreneurial training are extremely important. Our interviewees repeatedly cited lack of livelihood as a source of vulnerability for Yolanda survivors.

\subsection{Aid allocation}

In the mid-term recovery phase numerous agencies handed out free cash without any need to contribute labour to the projects. This created a competition between the different aid agencies and within communities, as people naturally took the free cash rather than work for it. Free cash can also create a dependency mentality, as people begin to rely on further donations to sustain them. In the longer term, vulnerability cannot be countered by dole outs. It is, therefore, important that aid enables survivors the freedom to pursue efficient, contextually appropriate and sustainable livelihood strategies. In other words, after the initial emergency phase, government agencies and aid agencies should focus on capability building and the building of 'livelihood' buffers in order to minimise risk, stabilise livelihood and reduce vulnerability. The failure to diversify was evident in relation to fisheries and coconut farming as detailed below.

Typhoon Yolanda directly affected 39,000 fisher families. Multiplier effects meant that up to 400,000 people, whose livelihoods were indirectly related to fisheries, were affected (ReliefWeb 2014: 15). The Food Security and Agriculture Cluster (FSAC) organised a mechanism to monitor the distribution of clearly needed boats. However, we found 
numerous examples of duplicated aid. Fishermen were favoured recipients of equipment and aid but in some cases individual fisherman received up to three boats (with others not receiving even one), by different donors. ${ }^{7}$ This is because boat donations make good headlines and positive public relations for the donor agencies, which could encourage more donations to that particular agency. Poorly planned over-generosity often results in greater competition among the fisherfolk, as boats were also given to non-fishers. The increase in fishing activity depletes the fishery resources and threatens the sustainability of livelihoods. Alternatively, boats are accepted but lie unused and are simply a waste of muchneeded resources.

Many of our interviewees also indicated that there were sectoral preferences on helping fishermen, but very little on farmers, factory workers and people working in the informal sector. The government has come under criticism as farming programs 'do not necessarily address the issue of agriculture backwardness and underdevelopment that should be the priority of action' (IBON 2016); in other words, the overarching social order remains the same and farmers remain vulnerable. Most farmers affected by Yolanda rely on coconut farming for their livelihood, but most of the trees were destroyed by the storm and it will take several years for coconut seedlings to grow full-term. However, coco farmers received scant assistance. According to some of our informants, farmers need support for alternative crops suitable for the area, alternative livelihoods, as well as support for irrigation and cooperative building. Without this support, farmers are trapped in a cycle of insecurity as they lack the freedom or capacity to build sustainable livelihood solutions.

\subsection{Gender and livelihood}

Another phenomenon in evidence was that many livelihood options are gender-biased. As evidenced above, livelihood programmes tend to focus on the rehabilitation of fisherfolks, who are usually men. Darina Romero, barangay captain of Barangay Libertad in Palo ${ }^{8}$, explained that the women in her community:

Want to do a lot more, to bring in income and also make life easier for our community. We would be grateful if there are some kind of livelihood options available to us, such as an investment to buy an oven so we can start a bakery cooperative, or a weaving cooperative, so we can weave and watch over our kids, and make money at the same time [....] I have asked the government again and again but there are no available funds.

There were some international organisations and donors, such as the International Labour Organisation (ILO), the Japan Ministry of Foreign Affairs, and CARE that recognised the specific impact of the disaster on women. 50 per cent of their efforts targeted female worker beneficiaries with considerable success. Of the 3354 workers provided with decent work by the ILO, 1536 were women (ILO 2014), while CARE have supported 60 women entrepreneurs to build sustainable enterprises (CARE 2015). However, these examples are few and far between. In Tacloban, the social arm of the Catholic Church has an ongoing training program in dressmaking for women. In Sta. Cruz, Tanauan, the Japanese International Cooperation Agency (JICA) is developing a milkfish (bangus) processing facility

\footnotetext{
7 Interviews with barangay captains in 2015 .

8 Interview, 11 November 2016.
} 
that will be turned over to a women's association. However, these programmes are selective and targeted, with very few beneficiaries.

We also found that the (re)creation of women focused sari-sari store entrepreneurial activity met with mixed success. Sari-sari stores are small local stalls that sell a variety of household goods. Typically, goods are sold in small units or sachets that are affordable to 'micro consumers' otherwise known as the 'bottom of the pyramid market' (Prahalad 2014: 6). Sari-sari store schemes were promoted by a number of donors including USAID in partnership with Coca Cola and Procter and Gamble (US Embassy 2015). The stores were lauded (Padua 2014) as a means to foster entrepreneurial spirit and were highly desired as evidenced in our focus group discussions with women.

However, the sari-sari store initiatives suffered from a number of problems including oversupply. In 2016, all of the barangay officials that we interviewed reported that the number of stores had increased substantially after Yolanda, typically a figure of 30 per cent was cited. This meant that storeowners in poor communities were competing for limited customers with low spending power. We also found that beneficiaries of the sari-sari store schemes were sometimes out of their depth in their new role as 'micro-entrepreneurs'. Whilst business training was given, including by the local government, we were also told of cases where beneficiaries could not afford to buy new stock after their start-up capital ran out or they simply spent the money they were given on household expenditure ${ }^{9}$ and the business subsequently collapsed. It seemed that sari-sari store ownership worked best with experienced owners; those who had no experience of running a small business tended to fare less well in some cases.

In a Typhoon Yolanda response review published in April 2014, women interviewees cited sustainable livelihood as a primary need (Sanderson and Willison 2014: 4). We repeatedly heard calls for more women's livelihood options during our interviews and FGDs in all 3 years of our data gathering. It is vital to scale up women's cooperative or livelihood options and extend them to other regions, especially those that are more rural and less accessible. It is also evident from the examples above that post-disaster livelihood strategies must acknowledge women's role as caregivers and make reasonable adjustments that allow women to maximise their capabilities without compromising the care of their families.

If governmental and non-governmental agencies fail to adapt their strategies to the needs of women, or only pay lip service to gender based issues, they are discriminating against an already vulnerable group and reinforcing the social structure in ordinary times. This has a knock-on effect to the wider community as 'the security of children and other dependents is at risk when women's own lives are insecure' (Enarson 2014: 46). Even agencies that are full of good intentions may inadvertently add to the insecurity of these women if they do not take full account of their capabilities and commitments, such as their dual roles as workers and family caregivers. As mentioned in the opening paragraphs of this article age, gender, disability, sexuality, ethnic difference, locality and levels of wealth all contribute to how vulnerability and insecurity is experienced. Livelihood assistance that fails to adequately account for the practical limitations of certain groups will fail. Focus group discussions indicated that survivors with complex needs, such as women with children with disabilities, found it extremely difficult to juggle their caring responsibilities with the training and livelihood options offered by relief agencies. Sustainable livelihood

\footnotetext{
${ }^{9}$ Interview, Tacloban Vice Mayor Jerry Yaokasin (2017).
} 
strategies have to take account of complex needs, cannot be gender blind and have to be built from the bottom up.

\section{Livelihood: a sustainable rebuilding?}

The communities assessed in this article were still undergoing rehabilitation and rebuilding more than 6 years after Typhoon Yolanda. In the aftermath of Yolanda, INGOs and NGOs were extremely active, but by November 2016, only four to five international organisations/ NGOs were still active. A lack of sustainable livelihood, inadequate and unsafe housing, the inadequate provision of utilities such as water and electricity and incomplete infrastructures such as roads and drainage in the resettlement areas continue to threaten human security. Livelihood opportunities in the resettlement sites, situated mostly away from original areas of residence and work, are generally inadequate and based on micro-entrepreneurial schemes such as food vending, sari-sari stores, and manicure and pedicure treatments. Whilst efforts were made to monitor the viability of these businesses (Roca 2017), intense competition, a lack of economies of scale and low profit margins has led to a bare level of subsistence. Some traditional household livelihood strategies such as the raising of pigs were banned in the resettlements, thus depriving households of a much-needed source of income. We observed schemes such as quail egg production, funded by Operation Blessing, fail over the course of our visits to the communities due to lack of demand. Consequently, people are travelling back to their original places of residence in unsafe areas to engage in their former occupations.

The withdrawal of many aid agencies left people worse off than before as the drying up of material provision and livelihood options coincided with their exit. The sheer volume of aid created by the extraordinary conditions that initially inundated Yolanda affected areas contributed to a dependence mentality in various communities. Significant free handouts, and a lack of other viable options created expectations of further assistance. Many of the interviewees we spoke to were extremely concerned as rehabilitation processes were turned over to the government, whom they considered to be the least active actor in the rehabilitation process.

Government agencies are mandated by existing national laws and frameworks and help rebuild local communities. However, work needs to be done on inter-agency and community coordination to enhance effective community rehabilitation. Agencies working in the aftermath of any disaster should concern themselves with 'the stability and security of people's capabilities' (Gasper and Truong 2005: 377). New opportunities could be offered to the survivors, capitalising on the resources and knowledge available within the region and local communities. Social and material reconstruction could come about through new, locally sensitive and more proactive ways of doing things.

Livelihood transformation programs that enable marginalized communities to reduce vulnerability through stronger social resilience should be promoted. In many of the barangays we visited, locals proposed livelihood alternatives that would actually be sustainable even when external assistance stops. We heard suggestions utilising local resources that are readily available in ordinary times, such as sand and cement factories, bakery and sewing and other forms of cooperatives. We heard calls for gender focused livelihood programs. However, the reality is that communities and individuals have little control over the creation of 'buffers' or the trajectory of their recovery, which are mostly initiated by external stakeholders who are only privy to the 'extraordinary' conditions. This entrenches them in 
their marginalized position in society in the pre-disaster context. They remain vulnerable and powerless and resilience remains an aspiration rather than a sustainable reality.

Thus, crucial in post-disaster livelihood recovery are DRRM plans prepared by national and local governments, together with partner agencies and communities, which anticipate possible losses and prepare for sustainable alternative livelihoods. In the three localities, we investigated there were no comprehensive local DRRM plans, which were mandated by law, before Typhoon Yolanda hit in 2013. In Tacloban, the city's DRRM plan was only created in 2016. In Palo, there was a draft DRRM plan in existence in 2013 but it was not yet approved when Yolanda struck. Tanauan appeared to be the most advance in this respect, as the municipality was the first local government to submit a recovery roadmap or plan to the national government after Yolanda. But across all three locations plans were crafted under 'extra-ordinary' circumstances. Overall national and local government agency data and monitoring systems were inadequate and lacked systematic coordination with different stakeholders. This led to duplication of aid, neglect of certain areas and sectors and waste via oversupply in others.

To summarise, if livelihood is to be sustainable then it must enhance pre-disaster skills and productive assets, be scaled up and the supply of goods produced must be linked to market demand. This is why it is important that sustainable livelihoods should be crafted for 'ordinary' (pre-disaster) rather than 'extraordinary' (post-disaster) conditions. Economic booms based on the initial rehabilitation phase will inevitably collapse unless great care is taken to foster longer-term demand for goods and services and the capability to meet this demand. If local demand collapses or access to markets further afield is impractical then even initially functioning livelihood projects will be doomed to failure. For livelihood strategies to be sustainable in the long run, they must be cognizant of 'normal' (or ordinary) realities such as care giving duties, ease of access to the workplace, weak or corrupt governance and exposure to flooding or drought. All these should be factored in local DRRM plans that should anticipate future disasters.

\section{Conclusion}

Before Typhoon Yolanda, many of the population in Tacloban, Palo and Tanauan living in low-lying coastal areas were vulnerable to inundation during typhoons (Lagmay et al. 2015). In some locations, this is still the case. Many residents in impoverished coastal barangays lived on the shore, or even over, the water with houses supported by wooden or bamboo stilts. The communities were chronically vulnerable to the elements. The capacity to build buffers against shocks or stresses to livelihood or to diversify activity was somewhat limited in these communities. People did not have the freedom to move away from the sea as land was scarce and livelihood opportunities were tied to proximity to the sea and other nearby means of making a living. Meanwhile, attempts at diversification were sometimes hindered by the inexperience of 'micro-entrepreneurs', intense competition over limited local markets and the piecemeal relocation of communities to higher ground.

There needs to be a carefully managed transition between emergency cash for work or cash for no work programs and diverse and sustainable livelihood building. Cosmetic postdisaster relief strategies that result in similar or equal but different vulnerabilities do not result in resilience. Similarly, the restoration of a pre-disaster status quo does not equate to resilience if suboptimal pre-disaster socio-economic structures remain entrenched. People and communities remain vulnerable under such conditions as they cannot effectively 
mitigate the risks that they face. This vulnerability is experienced unevenly. Certain livelihood sectors such as fishermen, farmers and own account workers; and certain demographics, such as women and the elderly, were particularly vulnerable.

The overarching objective of this article has been to critically assess the livelihood strategies that were used to reduce individuals' and communities' vulnerability in the aftermath of Yolanda. It appears that despite the significant relief and rehabilitation effort in the aftermath of the Typhoon Yolanda, individuals and communities in the areas we studied remain vulnerable. They are functioning, and people often see themselves as resilient. However, they still face a range of obstacles that impede the building of buffers against future shocks and stresses as most strategies are tailored in, and towards, 'extraordinary' conditions. Post-disaster livelihood assistance often failed to account for actual need, the sustainability of projects, pre-existing skills sets or caregiving responsibilities. Complex vulnerabilities experienced by women, the elderly, and those tasked with caring for people with disabilities were often overlooked. Coordination mechanisms and legal frameworks that should have anticipated these considerations were often either ignored or weakly implemented. The local governments that were supposed to be at the frontline of DRRM work were unprepared, overwhelmed, and caught off-guard by Yolanda and its aftermath. It also appears that participatory mechanisms where substantial community inputs are considered, especially in livelihood plans, were lacking.

Overall resilience must be about bouncing 'forward' rather than bouncing 'back' to an improved socio-economic normalcy, especially for the most vulnerable in society. For livelihood to be sustainable, we need to address pre-disaster social vulnerability entrenched by multiple factors such as gender and other protected characteristics. Post-disaster resilience can be meaningfully related to sustainable livelihood but bringing about change that builds capacity and alleviates vulnerability is key. Across cases this could include a realistic examination of local environmental factors and natural resource dependence, culture and the role of women, infrastructure and market access for locally produced goods and services and the extent to which livelihood can be organised on a collective basis. Government agencies and non-governmental organisations should also consider further the diverse earning streams of the poor that can be adjusted to account for factors such as caregiving, seasonal changes in the weather or market demand in holiday or celebration periods. We observed strategies that neglected empowerment, capacity building and the importance of giving voice to individuals and their communities, especially the most vulnerable ones. If agency is to be effectively built, survivors should be helped to identify for themselves the livelihood strategies that reduce vulnerability and help build secure futures.

Finally, in the future DRRM strategies need to mainstream sustainable livelihood into development planning in ways that boost capabilities and reduce vulnerability. A systematic mapping of vulnerability, even before disaster strikes, with the participation of local people and communities, could help aid agencies and governments identify policy shortcomings and become more reflective about what disaster relief could and should achieve, particularly in building sustainable livelihoods.

Funding This research is funded by an ESRC/DFID Joint Fund Poverty Alleviation Grant (ES/M008932/1, $£ 347,000.00$ ). Dr. Pauline Eadie is Primary Investigator and Prof. May Tan-Mullins (University of Nottingham, Ningbo) and Prof. Maria Ela Atienza (University of the Philippines Diliman) are Co-Investigators.

Open Access This article is licensed under a Creative Commons Attribution 4.0 International License, which permits use, sharing, adaptation, distribution and reproduction in any medium or format, as long as you give appropriate credit to the original author(s) and the source, provide a link to the Creative Commons 
licence, and indicate if changes were made. The images or other third party material in this article are included in the article's Creative Commons licence, unless indicated otherwise in a credit line to the material. If material is not included in the article's Creative Commons licence and your intended use is not permitted by statutory regulation or exceeds the permitted use, you will need to obtain permission directly from the copyright holder. To view a copy of this licence, visit http://creativecommons.org/licenses/by/4.0/.

\section{References}

Aldrich DP (2012) Building resilience: social capital in post-disaster recovery. University of Chicago Press, Chicago

Alexander DE (2013) Resilience and disaster risk reduction: an etymological journey. Nat Hazards Earth Syst Sci 13:2707-2716

Angeles LC, Hill K (2009) The gender dimension of the agrarian transition: women, men and livelihood diversification in two peri-urban farming communities in the Philippines. Gend Place Cult 16(5):609-629

Atienza ME, Eadie P, Tan-Mullins M (2019) Urban poverty in the wake of environmental disaster: rehabilitation, resilience and Typhoon Haiyan (Yolanda). Routledge, Abingdon and New York

Bacon P (2014) The politics of human security in Japan. In: Bacon P, Hobson C (eds) Human security and Japan's triple disaster: responding to the 2011 Earthquake, Tsunami and Fukushima nuclear crisis. Routledge, London, pp 22-38

Bambals R (2015) Human security: an analytical tool for disaster perception research. Disast Prevent Manag 24(2):150-165

Bankoff G (2003) Cultures of disaster: society and natural hazard in the Philippines. Routledge, London

Bebbington A (1999) Capitals and capabilities: a framework for analyzing peasant viability, rural livelihoods and poverty. World Dev 27(12):2021-2044

Berja C (2015) Poverty alleviation in the wake of Typhoon Yolanda: results of the 2015 survey of individuals in selected communities. http://www.projectyolanda.org/documents/project-yolanda-surve y-results-2015.pdf. Accessed 6 Feb 2020

Bhatt MR, Reynolds T (2012) Community-based disaster risk reduction: realizing the primacy of community. In: Emdad Haque C, Etkin D (eds) Disaster, risk and vulnerability: mitigation through mobilizing communities and partnerships. McGill-Queen's University Press, Montreal, pp 71-90

Borras SM Jr, Franco JC (2005) Struggles for land and livelihood: redistributive reform in agribusiness plantations in the Philippines. Crit Asian Stud 37(3):331-361

Brillantes AB (1998) Decentralised democratic governance under the local government code: a governmental perspective. Philipp J Public Admin XLII(1):38-57

Brown K, Westaway E (2011) Agency, capacity, and resilience to environmental change: lessons from human development, well-being, and disasters. Ann Rev Environ Resour 36:321-342

Cannon T, Twigg J, Rowell J (2003) Social vulnerability, sustainable livelihoods and disaster. Report submitted to DFID conflict and humanitarian assistance department (CHAD) and sustainable livelihoods support office

Cardona OD (2004) The need for rethinking the concepts of vulnerability and risk from a holistic perspective: a necessary review and criticism for effective risk management. In: Bankoff G, Frerks G, Hilhorst D (eds) Mapping vulnerability: disaster, development and people. Earthscan, London, pp 37-51

CARE (2015) Two years after Typhoon Haiyan: CARE response in numbers. http://www.care.org/sites/ default/files/documents/Philippines-Factsheet-2-Years-After-Haiyan.pdf. Accessed 6 Feb 2020

Chambers R (1995) Poverty and livelihoods: whose reality counts? Environ Urban 7(1):173-204

Chambers R, Conway G (1992) Sustainable rural livelihoods: practical concepts for the twenty-first century. Discussion paper no. 296. Institute for Development Studies, Brighton

Chmutina K, Bosher L (2015) Disaster risk reduction or disaster risk production: the role of building regulations in mainstreaming DRR. Int J Disast Risk Reduct 13:10-19

Cote M, Nightingale AJ (2012) Resilience thinking meets social change in socio-ecological systems (SES) research. Progr Hum Geogr 36(4):475-489

Dalisay SN, De Guzman MT (2016) Risk and culture: the case of Typhoon Haiyan in the Philippines. Disast Prev Manag 25(5):701-714

David CPC, Racoma BAB, Gonzales J, Clutario MV (2013) A manifestation of climate change? A look at Typhoon Yolanda in relation to the historical tropical cyclone archive. Sci Diliman 25(2):79-86 
Davidson-Hunt IJ, Berkes F (2003) Nature and society through the lens of resilience: towards a human-inecosystem perspective. In: Berkes F, Colding J, Folke C (eds) Navigating social-ecological systems: building resilience for complexity and change. Cambridge University Press, Cambridge, pp 53-82

De Haan L, Zoomers A (2005) Exploring the frontier of livelihood research. Dev Change 36(1):27-47

Delisle S, Turner S (2016) The weather is like the game we play: coping and adaptation strategies for extreme weather events among ethnic minority groups in upland Northern Vietnam. Asia Pacific Viewp 57(3):351-364

Eadie P (2019) Typhoon Yolanda and post-disaster resilience: problems and challenges. Asia Pacific Viewp 60(1):94-107

Enarson E (2014) Human security and disaster: what a gender lens offers. In: Bacon P, Hobson C, Cameron R (eds) Human security and natural disasters. Routledge, London, pp 37-56

Gaillard JC, Maceda EA, Stasiak E, Le Berre I, Espaldo MVO (2009) Sustainable livelihoods and people's vulnerability in the face of coastal hazards. J Coast Conserv 13(2):119-129

Gaillard JC, Fordham M, Sanz K (2015) Culture, gender and disaster: from vulnerability to capabilities. In: Kruger F, Bankoff G, Cannon T, Orlowski B, Schipper E (eds) Cultures and disasters: understanding cultural framings in disaster risk reduction. Routledge, London, pp 222-234

Gasper D, Truong TD (2005) Deepening development ethics: from economism to human development to human security. Eur J Dev Res 17(3):372-384

Ginige K, Amaratunga D, Haigh R (2009) Mainstreaming gender in disaster reduction: why and how? Disast Prev Manag Int J 18(1):23-34

IBON (2016) Food producers, poorer, hungry three years after Yolanda. http://ibon.org/2016/12/foodproducers-poorer-hungry-three-years-after-yolanda/. Accessed 4 Oct 2017

Intergovernmental Panel on Climate Change (IPCC) (2018) Special report: global warming of $1.5^{\circ} \mathrm{C}$. https://www.ipcc.ch/sr15/. Accessed 6 Feb 2020

International Labour Organisation (ILO) (2014) Typhoon Haiyan (Yolanda): integrated livelihood recovery for Typhoon Haiyan affected communities. http://www.ilo.org/wcmsp5/groups/public/-asia/-robangkok/-ilo-manila/documents/publication/wcms_324771.pdf. Accessed 6 Feb 2020

International Labour Organisation (ILO) (2015) Philippine employment trends 2015: accelerating inclusive jobs through decent jobs. https://www.ilo.org/surveydata/index.php/catalog/1938/downl oad/15318. Accessed 6 Feb 2020

Kelman I, Gaillard JC, Lewis J, Mercer J (2016) Learning from the history of disaster vulnerability and resilience research and practice for climate change. Nat Hazards 82:129-143

Khoza S, Van Niekerk D, Nemakonde LD (2019) Understandings gender dimensions of climate smart agriculture adoption in disaster-prone smallholder communities in Malawi and Zambia. Disast Prev Manag 28(5):530-547

Lagmay AM, Agaton RP, Bahala MA, Briones JB, Cabacaba KM, Caro CV, Dasallas LL (2015) Devastating storm surges of Typhoon Haiyan. Int J Disast Risk Reduct 11:1-12

Manyena SB (2006) The concept of resilience revisited. Disasters 30(4):433-450

Marschke MJ, Berkes F (2006) Exploring strategies that build livelihood resilience: a case from Cambodia. Ecol Soc 11(1):42-58

Mitchell T, Harris K (2012) Resilience: a risk management approach. Overseas Development Institute, London

Mondragon AB (2015) The changing normal in Philippine climate, Rappler. https://www.rappler.com/ move-ph/issues/disasters/114004-changing-normal-philippine-climate. Accessed 7 Jan 2020

Morse S, McNamara N (2013) Sustainable livelihood approach: a critique of theory and practice. Springer, Dordrecht

National Operational Assessment of Hazards (NOAH) (n.d.) 'Yolanda (2013) Storm surge in Tacloban City, Leyte'. http://center.noah.up.edu.ph/yolanda-storm-surge-tacloban-city/. Accessed 6 Feb 2020

National Statistical Coordination Board (NSCB) (2015) E. Visayas Dislodges ARMM As Poorest Region. http://www.bworldonline.com/content.php?section=Nation\&title=e.-visayas-dislodgesarmm-as-poorest-region\&id=103965. Accessed 6 Jan 2020

OCHA/UNEP (2014) Typhoon Haiyan (Yolanda) Philippines: environmental situational overview. https ://reliefweb.int/report/philippines/typhoon-haiyan-yolanda-philippines-environmental-situationa 1-overview-14-january. Accessed 6 Jan 2020

Padua, R (2014) Tacloban sari-sari stores back in business. The Philippine star. https://www.philstar. com/nation/2014/05/18/1324263/tacloban-sari-sari-stores-back-business. Accessed 6 Feb 2020

Philippine Statistics Authority (2016) Regional and social economic trends: eastern visayas region, vol VIII. Republic of the Philippines: Regional Statistical Services Office, Philippines

Philippines News Agency (2016) Eastern Visayas unemployment rate dips. Manila Bulletin. http://www. mb.com.ph/eastern-visayas-unemployment-rate-dips/. Accessed 5 Jan 2017 
Prahalad CK (2014) The fortune at the bottom of the pyramid: eradicating poverty through profits, 5th edn. Prentice Hall, Upper Saddle River

ReliefWeb (2014) Typhoon Haiyan (Yolanda): early recovery livelihoods and agriculture plan. Philippine Humanitarian Country Team. https://reliefweb.int/report/philippines/typhoon-haiyan-yolandaearly-recovery-livelihoods-and-agriculture-plan-february. Accessed 6 Feb 2020

Rigg J, Law L, Grundy-Warr C, Tan-Mullins M (2008) Grounding a natural disaster: Thailand and the 2004 Tsunami. Asia Pacific Viewp 49(2):137-154

Roca HJ (2017) '802 North Tacloban residents to get DTI, City government livelihood assistance. City of Tacloban. http://tacloban.gov.ph/802-north-tacloban-residents-to-get-dti-city-govt-livelihood -assistance/\#.Wu8ewy-ZMQ8. Accessed 6 May 2018

Rodin J (2015) The resilience dividend. Profile Books, London

Sanderson D (2000) Cities, disasters and livelihoods. Risk Manag 2(4):49-58

Sanderson D, Willison ZD (2014) Philippines Typhoon Haiyan response review. Disasters Emergency Committee and Humanitarian Coalition. http://www.dec.org.uk/sites/default/files/pdf/dec_hc_haiya n_review_report_2014.pdf. Accessed 6 Jan 2020

Scoones I (1998) Sustainable rural livelihoods: a framework for analysis. IDS Working Paper 72. https:// www.ids.ac.uk/publication/sustainable-rural-livelihoods-a-framework-for-analysis. Accessed 6 Feb 2020

Scoones I (2009) Livelihood perspectives and rural development. J Peasant Stud 36(1):171-196

Secret Aid Worker (2015) Secret aid worker: two years after Haiyan, the aid economy is flourishing, the guardian. https://www.theguardian.com/global-development-professionals-network/2015/nov/10/ secret-aid-worker-two-years-after-haiyan-the-aid-economy-is-flourishing. Accessed 6 Jan 2020

Siar SV (2003) Knowledge, gender and resources in small scale fishing: the case of Honda Bay, Palawan, Philippines. Environ Manag 31(5):569-580

Sok S, Xiaojiang Y (2015) Adaptation, resilience and sustainable livelihoods in the communities of the Lower Mekong Basin, Cambodia. Int J Water Resour Dev 31(4):575-588

Tabuga AD, Mina CD (2011) Disability and gender: the case of the Philippines. PIDS discussion paper series no. 2011-32. https://www.econstor.eu/bitstream/10419/126869/1/pidsdps1132.pdf. Accessed 6 Jan 2020

Taheri Tafti M, Tomlinson R (2015) Best practice post-disaster housing and livelihood recovery interventions: winners and losers. Int Dev Plan Rev 37(2):165-185

Tanner T, Zaman RU, Acharya S, Gogoi E, Bahadur A (2019) Influencing resilience: the role of policy entrepreneurs in mainstreaming climate adaptation. Disasters 43(S3):S388-S411

Tanyag M (2018) Resilience, female altruism and bodily autonomy: disaster induced displacement in the Post-Haiyan Philippines. Signs J Women Cult Soc 43(3):563-584

Trujillo M, Baas S (2015) Mainstreaming disaster risk reduction in agriculture: an assessment made against the Hyogo framework for action UNISDR input paper. https://www.unisdr.org/2014/docs/ un-drr/FAO-GAR15-InputPaper.pdf. Accessed 7 Jan 2020

United Nations International Strategy for Disaster Risk Reduction (UNISDR) (2009) UNISDR terminology on disaster risk reduction. UNISDR, Geneva. http://www.unisdr.org/we/inform/publicatio ns/7817. Accessed 5 Jan 2020

United States Agency for International Development (USAID) (2014) Philippines Typhoon Haiyan fact sheet \#22, fiscal year (FY) 2014. https://www.usaid.gov/sites/default/files/documents/1866/phili ppines_ty_fs22_04-21-2014.pdf. Accessed 3 Jan 2020

United States Embassy (2015) US hands over new facilities and livelihood support. https://ph.usemb assy.gov/us-hands-over-new-facilities-and-livelihood-support/. Accessed 6 Feb 2020

Usamah M, Handmer J, Mitchell D, Ahmed I (2014) Can the vulnerable be resilient? Co-existence of vulnerability and disaster resilience: informal settlements in the Philippines. Int $\mathrm{J}$ Disast Risk Reduct 10(1):178-189

Valenzuela B (2015) Head of Tacloban City information office. Interview

Wamsler C (2006) Mainstreaming risk reduction in urban planning and housing: a challenge for international aid organisations. Disasters 30(2):151-177

Weichselgartner J, Kelman I (2014) Geographies of resilience: challenges and opportunities of a descriptive concept. Prog Hum Geogr 39(3):249-267

Wisner B, Blaikie P, Canon T, Davis I (2004) At risk: natural hazards, people's vulnerability and disasters, 2nd edn. Routledge, London

Yamagata T (2015) Livelihood: how do PWDs earn a living. In: Mori S, Reyes CM, Yamagata T (eds) Poverty reduction of the disabled: livelihood of persons with disabilities in the Philippines. Routledge, London, pp 71-89

Yaokasin J (2017) Vice mayor Tacloban. Interview 
Yumarni T, Amaratunga D (2018) Gender mainstreaming as a strategy to achieve sustainable post-disaster reconstruction. Built Environ Asset Manag 8(5):544-556

Publisher's Note Springer Nature remains neutral with regard to jurisdictional claims in published maps and institutional affiliations. 